\title{
The ethical intention of marketing students: the role of ethical ideologies, Machiavellianism and gender
}

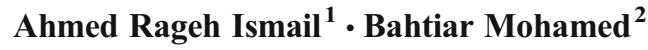

Published online: 16 November 2016

(C) Springer International Publishing AG 2016

\begin{abstract}
This study investigates the relationship between ethical ideologies, Machiavellianism, perceived ethical problem, gender and ethical intention. The results from a survey of students in marketing classes from an Australian university branch campus in Malaysia revealed that relativism and Machiavellianism have negative impact on ethical intention of students. However, idealism and perceived ethical problems have positive impacts on their ethical intention. Moreover, the study found that gender is not a determinant of the ethical intentions of students. This study is attempting to improve our understanding of the ethical issues existing in one of the emergent markets (i.e. Malaysia). Additionally, it offers some implications for marketing educators.
\end{abstract}

Keywords Marketing Ethics $\cdot$ Idealism $\cdot$ Relativism $\cdot$ Machiavellianism $\cdot$ Ethical intention

\section{Introduction}

Business ethics has been of an increasing interest to academics since 1960s (De George 1987; Tsalikis and Fritzsche 1989; Nill and Schibrowsky 2007; Schlegelmilch and Oberseder 2010). Similarly, the ethical decision making of marketers has been receiving attention from scholars over the past decades (Dubinsky and Loken 1989; Singhapakdi 2004; Mullin Marta et al. 2004; Singhapakdi et al. 2013). Marketing educators play an important role in communicating ethical knowledge and shaping the next generation of marketers' attitudes towards marketing practices (Loe and Ferrell 2001). Now, more than ever, marketing educators need to ensure that they are teaching

Ahmed Rageh Ismail

Ahmed.r@curtin.edu.my

1 Marketing Department, School of Business, Curtin University, Miri Campus, Miri, Malaysia

2 Communication Department, School of Multimedia Technology and Communication, Universiti Utara Malaysia, Sintok, Malaysia 
ethics effectively. In pursuit of this, it is important to have a good understanding of the different factors by which students make ethical decisions. Noting that little research has addressed the factors influencing marketing students' ethical intention (Gaedeke et al. 1992; Singhapakdi and Vitell 1994; Yoo and Donthu 2002; Singhapakdi 2004), the current study is attempting to fill in this gap in the literature. It identifies some variables such as relativism, idealism, perceived ethical problem, Machiavellianism and gender as major determinants of the ethical intention of marketing students or future marketing professionals.

The importance of this study is twofold: For educators, it helps to gain better understanding of important ethics variables that would guide educators in raising student's ethical standards in a new context (Malaysia). For students, it will help them to avoid potential conflicts, be well prepared for business world, and succeed in their marketing career. This article is organized as follows. The next section reviews the literature on ethical ideologies, perception of ethical problem, Machiavellianism and gender. Then, the article develops a research model and research hypotheses of the relationships among the study variables. The conducted survey will be explained in the methodology section. Finally, implications of the findings and conclusions are put forward.

\section{Literature review and hypotheses development}

\section{Ethical ideologies}

Ethical ideology is defined as "a system of ethics used to make moral judgments, which offers guidelines for judging and resolving behavior that may be ethically questionable" (Henle et al. 2005, p. 219). Ethical ideology is a major determinant of marketers' ethical decisions (Schlenker and Forsyth 1977; Forsyth 1980, 1992). There are two basic dimensions of personal moral philosophies, idealism and relativism. Idealism is a personal ethic approach defined as the degree to which individuals assume that desirable consequences can always be obtained, provided that the right actions are taken (Forsyth 1980). As Forsyth (1992) stated, "Highly idealistic individuals feel that harming others is always avoidable" (p. 462), suggesting that high idealists will be less likely to engage in unethical behaviors. Conversely, less idealistic individuals believe that harm is unavoidable in some cases, and that undesirable consequences will often be mixed in the desired ones (Wang and Calvano 2015).

The second dimension, relativism, refers to the degree to which people rejects universal moral rules and norms when making ethical judgments (Forsyth 1980, 1992). Highly relativistic individual tend to rely more on the circumstances and personal attitudes than moral principles when making an ethical judgment (Forsyth 1992). Less relativistic, however, have more faith in moral principles, norms, or laws. They use those universal principles to define for them what is right and what is wrong (Wang and Calvano 2015). Highly idealistic marketers found to exhibit higher honesty and integrity than their relativistic counterparts (Vitell et al. 1993; Singhapakdi et al. 1995). As a result, rooted in the two personal moral philosophies and consistent with the above conceptualization, it is hypothesized that idealism will positively influence the ethical intention of marketing students in a positive way, whereas relativism will 
influence their ethical intention in a negative way. Therefore, these hypotheses were put forward:

H1: Idealism will be positively related to ethical intention of marketing students.

$\mathrm{H} 2$ : Relativism will be negatively related to ethical intention of marketing students.

\section{Perception of an ethical problem}

Perception of an ethical problem is salient prerequisite for the ethical decisionmaking process Hunt and Vitell (1986). "This perception of an ethical problem situation triggers the whole process depicted by the model. If the individual does not perceive some ethical content in a problem situation, subsequent elements of the model do not come into play" (Hunt and Vitell 1986, p. 7). Marketing managers who perceive ethical problems when confronted with ethical dilemma are more likely to take action to remedy them (Singhapakdi and Vitell 1990). In the same vein, it is expected that a marketing students who perceives an ethical problem in a situation will tend to be more ethical in his or her intention than a marketing student who perceives an ethical problem less readily. Therefore, an assumption has been made that:

H3: Perceived ethical problem will be positively related to ethical intention of marketing students.

\section{Machiavellianism}

Machiavellianism is referred to as an amoral approach that employs devious, manipulative tactics and ignores the needs and rights of others for personal gain (Stylianou et al. 2013). The word Machiavellianism emerged from Niccolo Machiavelli (14691527), political philosopher and author of The Prince. He suggested that rulers who ignore their ethics and values would be more successful than those who rule truthfully and honestly (Machiavelli 1965). The Machiavellianism construct has originated after the work of Geis and Christie (1970). High Machiavellian individuals "manipulate more, win more, are persuaded less, persuade others more, and otherwise differ significantly from their low Machiavellian counterparts." (Geis and Christie 1970, p.213). Previous studies have established relationships between Machiavellianism and a plethora of outcomes such as; lack of empathy (Paal and Bereczkei 2007), tax avoidance (Shafer and Simmons 2008), stealing (Harrell and Hartnagel 1976), engaging in revenge-seeking behavior (Meyer 1992), or lying (Fletcher 1990). In general, Machiavellians are less ethical (Hegarty and Sims 1978, 1979). Thus, this study postulates that Machiavellianism will be negatively related to ethical intention of marketing students.

H4: Machiavellianism will be negatively related to ethical intention of marketing students. 


\section{Gender}

Gender is more often examined as an important individual characteristic influencing ethical decision making (Burton and Hegarty 1999; Roxas and Stoneback, 2004). Several business ethics studies (Ruegger and King 1992; Whipple and Wolf 1991; Ford and Richardson 1994; Dawson 1995; Lane 1995; Borkowski and Ugras 1998) reported that males tend to act less ethically than their female counterparts to ethical issues. That difference between genders can be attributed to socialization. According to gender socialization theory, males and females are taught how to socially behave in accordance with the norms, values, and beliefs of group membership as men or women, a process which known as gender socialization.

Different moral orientations can be a result of gender socialization. Males and females are expected to act in different ways in response to the same set of ethical circumstances (Kohlberg 1984). For instance, females associate moral questions with problems of care and compassion ('care orientation'), while males relate moral questions to problems of justice and rights ('justice orientation') (Gilligan 1982). In light of the above literature, one would expect females generally to be more ethically sensitive in their perceptions of marketing practices than males because females are more likely to discern unethical behaviors (Stylianou et al. 2013). Thus, the study proposes that female students to be more ethical in their intentions than their counterparts.

H5: Female marketing students will tend to be more ethical in their intentions than male marketing students.

\section{Research methodology}

\section{Participants}

Students enrolled in undergraduate marketing classes in Curtin University - Malaysia Campus were selected as the sample. Students completed a self-administered questionnaire that included the study variables. The data were collected by administering questionnaires in classes. There are 113 usable cases for this study, with a $74.3 \%$ female and $25.7 \%$ male and their age ranged between 18 and 25 years old. A power analysis was performed and confirmed that this was an adequate sample size.

\section{Measures}

Machiavellianism was measured using Mach IV scale borrowed from Geis and Christie (1970). Ethics Position Questionnaire (EPQ) developed by Forsyth (1980) was adopted to measure the personal moral philosophies of students. The EPQ has two subscales: idealism and relativism. Both scales contain ten items. Typical idealism items are "A person should make certain that their actions never intentionally harm another even to a small degree" and "It is never necessary to sacrifice the welfare of others." Examples of typical relativism items are "Questions of what is ethical for everyone can never be resolved because what is moral or immoral is up to the individual" and "What is ethical varies from one situation and society to another." A7- point Likert-type scale ranging 
from completely disagree (value of 1) to completely agree (value of 7) was used. The scores for each respondent were computed by summing the scores of all idealism or relativism items. Therefore, a high idealism value indicating that the respondent tends to rely heavily on universal moral rules when making moral judgments. A high relativism value, on the other hand, indicates that the respondent tends to rely less on universal moral rules when making moral judgments. Both idealism and relativism scales in this study appear to be reliable, with coefficient 0.84 and 0.75 .

In this study, perception of ethical problem and ethical intention were measured by means of two marketing ethics scenarios developed by Dornoff and Tankersley (1975) and Reidenbach et al. (1991). Consistent with previous research in marketing ethics (e.g., Singhapakdi and Vitell 1990; Sparks and Hunt 1998), perceived ethical problem was measured directly by asking the respondents whether the situation described in each of these scenarios involves an ethical problem. Specifically, the respondents were asked to express their degree of agreement or disagreement on a 7-point Likert type disagree/agree scale with the statement, "The situation above involves an ethical problem. A higher score indicates a stronger perception that the situation depicted in the scenario involves an ethical problem, and vice versa. Ethical intention was also measured by asking respondents to indicate their agreement or disagreement with each of the two scenarios, using this statement his statement "I would act in the same manner as [the marketer] did in the above scenario." Given that the scenarios used are examples of marketing behaviors that are generally considered to be unethical (i.e. overeager salesperson and failure to honor warranty), an agreement (higher scores) with the actions by the marketers depicted in the scenarios would be interpreted as a less ethical intention than a disagreement (lower scores). Therefore, the scores were reversed before analyses; higher scores can now be interpreted as more ethical intention.

\section{Analysis and results}

This study tested the effects ethical ideologies, perceived ethical problems, Machiavellianism and gender on ethical intentions using multiple regression analysis. As a preliminary step, however, a correlation analysis of all variables in this study was conducted. The results indicate that the two dimensions of personal moral philosophies, idealism and relativism are significantly correlated to ethical intentions in the two ethical scenarios tested. Moreover, Machiavellianism and perceived ethical problem are significantly correlated to ethical intentions in the two ethics scenarios. Gender of marketing students, however, is not significantly correlated to ethical intentions in the two scenarios.

The effects of idealism, relativism, Machiavellianism, perception of ethical problem and gender on ethical intentions for both scenarios are shown in Table 1. The results indicated that idealism has a significant influence on ethical intentions in the first scenario. However, the relationship is insignificant in the second scenario. Therefore, H1 is partially supported. The results also indicate that relativism has a significant influence on ethical intentions as hypothesized for two scenarios, providing support for $\mathrm{H} 2$. Additionally, $\mathrm{H} 3$ is generally supported and the results revealed that the greater the perception of ethical problem in an ethical dilemma, the more likely the students to have an ethical intention. Concerning the potential role of Machiavellianism as 
Table 1 Regression model: ethical intentions

\begin{tabular}{lrrr}
\hline Variables & Beta & $t$ & $P$ \\
\hline Model for scenario 1: overeager salesperson ${ }^{\mathrm{a}}$ & & & \\
$\quad$ Idealism & 0.250 & 2.400 & 0.018 \\
Relativism & -0.208 & -2.128 & 0.036 \\
Machiavellianism & -0.276 & -2.896 & 0.005 \\
Perception of ethical problem & 0.187 & 1.988 & 0.049 \\
Gender & 0.066 & 0.732 & 0.466 \\
Model for scenario 2: failure to honor warranty & & & 0.117 \\
Idealism & 0.165 & 1.580 & 0.015 \\
Relativism & -0.231 & -2.472 & 0.000 \\
Machiavellianism & -0.325 & -3.599 & 0.003 \\
Perception of ethical problem & 0.290 & 3.048 & 0.806 \\
Gender & -0.022 & -0.246 & \\
\hline
\end{tabular}

a Adjusted $R^{2}=0.112, F=3.346$, Significant $\mathrm{F}$ less than 0.05

b Adjusted $R^{2}=0.190, F=5.369$, Significant $\mathrm{F}$ less than 0.05

predictors of ethical intentions, the results reveal that there is a negative relationship between Machiavellianism and ethical intention in both scenarios; providing support for H4. The results also indicate that gender is not significant predictor of ethical intention for two scenarios, as hypothesized. Therefore, H5 is rejected.

\section{Discussion and implications}

This study tested the effect of idealism, relativism, Machiavellianism, perception of ethical problem and gender on ethical intentions. The results from the survey of marketing students in Malaysia indicated that, in general, ethical ideologies and perception of ethical problems have a positive influence on their ethical intentions. On the contrary, Machiavellianism has a negative influence on the ethical intention of the students. The results also indicate gender of the respondent doesn't' have any influence on the ethical intention. Perhaps this is a surprising result is that contradicts the previous studies (Burton and Hegarty 1999; Roxas and Stoneback, 2004; Ruegger and King 1992; Whipple and Wolf 1991; Ford and Richardson 1994) which reported that male and females are significantly different in their ethical judgment. This finding is still consistent with few studies in ethics literature (Singhapakdi and Vitell 1990; Hegarty and Sims 1978; Geiger and O'Connell 1999; Hay et al. 2001) that showed insignificant effect of gender on ethical perceptions and action.

The results also indicated that the idealism and relativism dimensions of personal moral philosophies influence the ethical intention of marketing students. In other words, highly idealistic (less relativistic) students tend to be more ethical in their intention than less idealistic (highly relativistic). Singhapakdi (2004) suggested that idealistic decision making should be strongly emphasized in business ethics courses in order to discourage relativistic perspectives that often lead to ethically problematic 
decisions. Likewise, the current study urges marketing educators to discourage relativistic decision making among students by improving their moral reasoning skills by ethics-training (Loe and Weeks 2000). Furthermore, the study findings illustrate the strong need for ethics education and training to improve ethical behavior among future marketers. As stated by Loe and Ferrell (2001), there are several tools that have been used by marketing professor in teaching ethics. Those tools include: the use of cases, videos, ethics texts, use of business press articles. Those tools provide content that includes ethical issues and differing moral philosophies used by individuals when making ethical decisions which help in engaging student and professors in discussions. Similarly, the use of "storytelling" approach (Bush et al. 1997) and the use of ethical scenarios (Loe and Weeks 2000) are proved to be beneficial in ethics teaching.

The study also showed that Machiavellianism is a predictor for ethical decision among marketing students. It is an expected finding that is congruent with prior studies which reported strong relationship between Machiavellianism and ethical judgment (Shafer and Simmons 2008; Mudrack et al. 2012). The findings implies that being high on Machiavellianism will necessarily imply being low on ethical intention. Therefore, Machiavellianism also should be discouraged at the individual level,

The results also revealed that marketing students who perceive an ethical problem in a situation are more likely to have an ethical intention compared to those who don't perceive it. As a result, marketing educators should provide appropriate theoretical foundation to help students understand more about the ethical decisions. A useful technique here is the use of case studies (Ferrell et al. 2002).

\section{Limitations of the study and future research}

The survey was conducted among marketing students in only one university in Malaysia, thus limiting the generalizability of the findings. Future research should consider a larger sample size and from different countries. There are several other variables that have not been taken into consideration in this study such as religiosity, spirituality and values). Therefore, it is recommended for further studies to assess the impact of those variables on the ethical intention of students.

\section{References}

Borkowski, S.C., and Y.F. Ugras. 1998. Business students and ethics: a meta-analysis. Journal of Business Ethics 17: 1117-1127.

Burton, B.K., and W.H. Hegarty. 1999. Some determinants of student corporate social responsibility orientation. Business and Society 38(2): 188-205.

Bush, Victoria, Sharon Harris, and Alan Bush. 1997. Establishing ethical boundaries for service providers: a narrative approach. The Journal of Services Marketing 11(4): 265-277.

Dawson, L. 1995. Women and men, morality and ethics. Business Horizons 38(4): 61-68.

De George, Richard T. 1987. The status of business ethics: past and future. Journal of Business Ethics 6(3): 201-211.

Dornoff, R.J. and Tankersley, C.B. 1975. Perceptual differences in market transactions: a source of consumer frustration. The Journal of Consumer Affairs, pp.97-103.

Dubinsky, A.J., and B. Loken. 1989. Analyzing ethical decision making in marketing. Journal of Business Research 19(2): 83-107. 
Ferrell, O.C., Fraedrich, J. and Ferrell, L. 2002. Business ethics: Ethical Decision Making and Cases Houghton Mifflin Company Boston.

Fletcher, C. 1990. The relationships between candidate personality, self-presentation strategies, and interviewer assessments in selection interviews: an empirical study. Human Relations 43(8): 739-749.

Ford, R.C., and W.D. Richardson. 1994. Ethical decision making: a review of the empirical literature. Journal of Business Ethics 13(3): 205-221.

Forsyth, D.R. 1980. A taxonomy of ethical ideologies. Journal of Personality and Social psychology 39(1): 175.

Forsyth, D.R. 1992. Judging the morality of business practices: the influence of personal moral philosophies. Journal of Business Ethics 11(5-6): 461-470.

Gaedeke, R.M., C.A. Kelley, and D.H. Tootelian. 1992. Business students' perceptions of ethics in marketing. Journal of Education for Business 67(5): 294-299.

Geiger, M.Z., and B.T. O’Connell. 1999. Accounting student (sic) ethical perceptions: an analysis of training and gender effects. Teaching Business Ethics 2: 371-388.

Geis, F. and Christie, R. 1970. Overview of experimental research. Studies in Machiavellianism, pp.285-313.

Gilligan, C. 1982. In a different voice. Cambridge: Harvard University Press.

Harrell, W.A. and Hartnagel, T. 1976. The impact of Machiavellianism and the trustfulness of the victim on laboratory theft. Sociometry, pp.157-165.

Hay, D., P.M. Larres, P. Oyelere, and A. Fisher. 2001. The ethical perception of undergraduate students in computer related situations: an analysis of the effects of culture, gender and prior education. Teaching Business Ethics 5: 331-336.

Hegarty, W.H., and H.P. Sims. 1978. Some determinants of unethical decision behavior: an experiment. Journal of Applied Psychology 63(4): 451.

Hegarty, W.H., and H.P. Sims. 1979. Organizational philosophy, policies, and objectives related to unethical decision behavior: a laboratory experiment. Journal of Applied Psychology 64(3): 331.

Henle, C.A., R.A. Giacalone, and C.L. Jurkiewicz. 2005. The role of ethical ideology in workplace deviance. Journal of Business Ethics 56: 219-230.

Hunt, S.D., and S. Vitell. 1986. A general theory of marketing ethics. Journal of Macromarketing 6(1): 5-16.

Kohlberg, L. 1984. The psychology of moral development. In: Essays on Moral Development, Vol. 2, Harper and Row, San Francisco.

Lane, J.C. 1995. Ethics of business students: some marketing perspectives. Journal of Business Ethics 14(7): 571-80.

Loe, T.W., and L. Ferrell. 2001. Teaching marketing ethics in the 21st century. Marketing Education Review 11(2): 1-15.

Loe, T.W., and W.A. Weeks. 2000. An experimental investigation of efforts to improve sales students' moral reasoning. Journal of Personal Selling and Sales Management 20(4): 243-251.

Machiavelli, N. 1965. Discourses on the first ten books of Titus Livius. Durham: Duke University Press.

Meyer, H.D. 1992. Norms and self-interest in ultimatum bargaining: the prince's prudence. Journal of Economic Psychology 13: 215-232.

Mudrack, P.E., J.M. Bloodgood, and W.H. Turnley. 2012. Some ethical implications of individual competitiveness. Journal of Business Ethics 108: 347-359.

Mullin Marta, J.K., A. Singhapakdi, A. Attia, and S.J. Vitell. 2004. Some important factors underlying ethical decisions of Middle-Eastern marketers. International Marketing Review 21(1): 53-67.

Nill, Alexander, and John A. Schibrowsky. 2007. Research on marketing ethics: a systematic review of the literature. Journal of Macromarketing 27(3): 256-273.

Paal, T., and T. Bereczkei. 2007. Adult theory of mind, cooperation, Machiavellianism: the effect of mindreading on social relations. Personality and Individual Differences 43: 541-551.

Reidenbach, R.E., D.P. Robin, and L. Dawson. 1991. An application and extension of a multidimensional ethics scale to selected marketing practices and marketing groups. Journal of the Academy of Marketing Science 19(2): 83-92.

Roxas, M.L., and Stoneback, J.Y. 2004. The importance of gender across cultures in ethical decision-making. Journal of Business Ethics 50(2): 149-165.

Ruegger, D., and E.W. King. 1992. A study of the effect of age and gender upon student business ethics. Journal of Business Ethics 11(3): 179-186.

Schlegelmilch, Bodo B., and Magdalena Oberseder. 2010. Half a century of marketing ethics: shifting perspectives and emerging trends. Journal of Business Ethics 93(1): 1-19.

Schlenker, B.R., and D.R. Forsyth. 1977. On the ethics of psychological research. Journal of Experimental Social Psychology 13(4): 369-396. 
Shafer, W.E., and R.S. Simmons. 2008. Social responsibility Machiavellianism and tax avoidance. Accounting, Auditing and Accountability Journal 21: 695-720. H.

Singhapakdi, A. 2004. Important factors underlying ethical intentions of students: implications for marketing education. Journal of Marketing Education 26(3): 261-270.

Singhapakdi, A., and S.J. Vitell. 1990. Marketing ethics: factors influencing perceptions of ethical problems and alternatives. Journal of Macromarketing 10(1): 4-18.

Singhapakdi, A., and S.J. Vitell. 1994. Ethical ideologies of future marketers: the relative influences of Machiavelliamsm and gender. Journal of Marketing Education 16(1): $34-42$.

Singhapakdi, A., K.L. Kraft, S.J. Vitell, and K.C. Rallapalli. 1995. The perceived importance of ethics and social responsibility on organizational effectiveness: a survey of marketers. Journal of the Academy of Marketing Science 23(1): 49-56.

Singhapakdi, A., S.J. Vitell, D.J. Lee, A.M. Nisius, and B.Y. Grace. 2013. The influence of love of money and religiosity on ethical decision-making in marketing. Journal of Business Ethics 114(1): 183-191.

Sparks, J.R. and Hunt, S.D. 1998. Marketing researcher ethical sensitivity: Conceptualization, measurement, and exploratory investigation. The Journal of Marketing, pp.92-109.

Stylianou, A.C., S. Winter, Y. Niu, R.A. Giacalone, and M. Campbell. 2013. Understanding the behavioral intention to report unethical information technology practices: the role of Machiavellianism, gender, and computer expertise. Journal of Business Ethics 117(2): 333-343.

Tsalikis, John, and David J. Fritzsche. 1989. Business ethics: a literature review with a focus on marketing ethics. Journal of Business Ethics 8(9): 695-743.

Vitell, S.J., S.L. Nwachukwu, and J.H. Barnes. 1993. The effects of culture on ethical decision-making: an application of Hofstede's typology. Journal of Business Ethics 12(10): 753-760.

Wang, L.C., and L. Calvano. 2015. Is business ethics education effective? An analysis of gender, personal ethical perspectives, and moral judgment. Journal of Business Ethics 126(4): 591-602.

Whipple, T.W., and D.D. Wolf. 1991. Judgments of marketing students about ethical issues in marketing research: a comparison to marketing practitioners. Journal of Marketing Education 13: 56-63. Spring.

Yoo, B., and N. Donthu. 2002. The effects of marketing education and individual cultural values on marketing ethics of students. Journal of Marketing Education 24(2): 92-103. 